\title{
Near vision spectacle coverage and barriers to near vision correction among adults in the Cape Coast Metropolis of Ghana.
}

\author{
Michael Ntodie ${ }^{1,2}$, Sampson L Abu ${ }^{2}$, Samuel Kyei ${ }^{2}$, Samuel Abokyi ${ }^{2}$, Emmanuel K Abu ${ }^{2}$
}
1. Vision Science Research Group, School of Biomedical Sciences, Faculty of Life and Health Sciences, Ulster University, UK.

2. Department of Optometry, School of Health and Allied Sciences, College of Health Allied Sciences, University of Cape Coast, Ghana.

\begin{abstract}
:
Purpose: To determine the near vision spectacle coverage and barriers to obtaining near vision correction among adults aged 35 years and older in the Cape Coast Metropolis of Ghana.

Methods: A population-based cross-sectional study design was adopted and 500 out of 576 participants aged 35 years and older were examined from 12 randomly selected clusters in Cape Coast, Ghana. All participants underwent a comprehensive eye examination which included: distance and near visual acuities measurements and external and internal ocular health assessments. Distance and near refractions were performed using subjective refraction technique. Information on participants' demographics, near vision correction status, near visual needs and barriers to acquiring near vision correction were obtained through a questionnaire administered as part of the study.

Results: The mean age of participants was $52.3 \pm 10.3$ years of whom $280(56 \%)$ were females and $220(44 \%)$ were males. The near vision spectacle coverage was 25\%,33\% "met need" for near vision correction in the presbyopic population, and $64 \%$ unmet need in the entire study population. After controlling for other variables, age ( $5^{\text {th }}$ and $6^{\text {th }}$ decades $)$ and educational level were associated with "met need" for near vision correction $(\mathrm{OR}=2.7$ (1.55-4.68), $\mathrm{p}=0.00$, and $\mathrm{OR}=2.36(1.18-4.72), \mathrm{p}=0.02$ respectively). Among those who needed but did not have near vision correction, $64(26 \%)$ did not feel the need for correction, $55(22 \%)$ stated that they were unaware of available interventions, and $53(21 \%)$ found the cost of near vision correction prohibitive.

Conclusion: There was a low near vision spectacle coverage in this population which suggests the need for strategies on health education and promotion to address the lack of awareness of spectacle need and cost of services.

Keywords: Presbyopia, near vision, spectacle coverage, unmet needs, Ghana.

DOI: https://dx.doi.org/10.4314/ahs.v17i2.31

Cite as: Ntodie M, Abu SL, Kyei S, Abokyi S, Abu EK. Near vision spectacle coverage and barriers to near vision correction among adults in the Cape Coast Metropolis of Ghana. Afri Health Sci. 2017;17(2): 549-555. bttps:// dx.doi.org/10.4314/ahs.v17i2.31
\end{abstract}

\section{Introduction}

Presbyopia is an age-related physiological change in the eye which results in loss of ability to accommodate for near viewing, ${ }^{1}$ and generally occurs between ages 40 and 45 years or earlier with a female preponderance. ${ }^{1,2}$ The age-related change in presbyopia occurs primarily in the lens: lenticular growth, and changes in its elastic prop-
Corresponding author:
Michael Ntodie,
Department of Optometry,
School of Health and Allied Sciences,
College of Health Allied Sciences,
University of Cape Coast, Ghana.
Email: ntodiemichael@gmail.com

erties. This is observed clinically as a receded amplitude of accommodation. ${ }^{3}$ The impact of presbyopia on the quality of life, and the potential loss of productivity are remarkably high for both literate and illiterate populations. ${ }^{4-6}$ Yet, a simple and cost - effective intervention through provision of a pair of near- vision spectacles can easily help to address this visual disability. ${ }^{7}$ An average cost of near vision spectacle in Ghana is approximately \$5.8 Near-vision spectacle could be dispensed as single vision, bifocal or progressive eye glasses to meet near vision needs. ${ }^{2}$

Recent evidence suggests that the ageing population in Ghana is increasing and this could have implications for the visual needs of individuals in this age category., 90 Ageing is associated with an increased rate of eye diseases some of which are potentially blinding. ${ }^{11}$ The adult 
population in Ghana has varied occupational and recreational tasks some of which require extensive periods of near work. Occupations such as fishing, farming, dress making which are common in many Ghanaian communities, could potentially benefit from near vision spectacles corrections. ${ }^{12}$ Furthermore, proliferation of portable devices such as smart phones and their wider acceptance by both literates and illiterates in many developing countries including Ghana mean that near vision-related activities are not only limited to traditional reading. ${ }^{10}$ Efficient near vision tasks could be easily accomplished if there are near vision spectacle corrections available. Only two studies have reported on the prevalence of presbyopia in Ghana with little or no information on near vision spectacle coverage in those study populations. ${ }^{2,13}$ This study therefore sought to determine the near vision spectacle coverage and identify barriers to near vision correction among adults aged 35 years and older in the Cape Coast Metropolis, Ghana. This information is necessary to provide the basis for planning efficient near vision spectacle services.

\section{Materials and methods:}

\section{Study design, area and sample selection}

A population-based cross-sectional study in adults aged 35 years and older, who were randomly selected from 12 clusters in the Cape Coast Metropolis of Ghana was conducted. A minimum sample size of 576 was determined using the following the mathematical formula:

$\mathrm{n}=\mathrm{Z}^{2} \mathrm{pq} / \mathrm{d}^{2} \cdot{ }^{14}$

Where $\mathrm{n}=$ required sample size, $\mathrm{p}=$ expected prevalence, $q=(1-p), d=$ degree of accuracy. $(Z=1.96, p=55, d=5 \%)$. The value obtained was multiplied by 1.5 to account for design effect.

In accordance with a previous related study conducted in South Africa, ${ }^{15}$ the lower age boundary of 35 years for presbyopia was used in the current study. Cape Coast is the capital of the Central region of Ghana. It has one of the highest growth rates in adults aged 60 years and older. ${ }^{10}$ The educational and socio-economic backgrounds of adults varies and includes: teachers, traders, fishermen and women, and artisans. ${ }^{16}$ The area also has eight eye care facilities with different cadres of eye care professionals including: ophthalmologists (2), optometrists (16), and dispensing opticians (6) which should theoretically translate to improved refractive services and an adequate near vision spectacle coverage. These reasons informed the choice of this area for the study. The population in the Cape Coast metropolis is approximately 170,000, with $60 \%$ of the population in urban settlements. ${ }^{16,17}$ There are 18 settlements (clusters), and 12 (8 from urban and 4 from rural locations) were randomly selected. Using probability proportionate to size, participants were calculated for each cluster and those who met the inclusion criteria within each cluster were enumerated two days before the data collection day. Households were identified by "random-walk", and "the spinning bottle" technique was used to choose directions when the team came to an area with a junction within a cluster. ${ }^{18}$ Adults aged $\geq 35$ years within each household were enumerated until the required sample for the cluster was obtained. Participants selected were individuals resident in any of the selected settlements for more than three months, were without any ocular pathologies and presented with a distance, pinhole visual acuity better than or equal to $6 / 18$ in the worse seeing eye. ${ }^{14,18}$ An opinion leader (Assembly man), who was a resident of respective clusters assisted in identifying the boundaries of clusters as well as inhabitants in each cluster. The study was conducted at a common assembly point in each cluster such as community or health center.

\section{Study definition and examination procedures}

A presbyope in this study was defined as a participant needing an optical correction of $\geq+1.00 \mathrm{D}$ added to the best distance optical correction to improve near vision to a near visual acuity criterion of at least N8 line or better. ${ }^{19}$ The study team consisted of four experienced optometrists, a local health worker and a final year optometry student. Examination procedures consisted of distance visual acuity, measured under ambient outdoor illumination, and acuity charts were positioned to prevent reflections which could induce glare. Distance Snellen charts were used to measure visual acuity; a tumbling " $E$ " chart was used for illiterate participants and a letter chart for literate individuals. An external eye examination with a hand-held slit lamp biomicroscope and an internal examination with direct ophthalmoscope were done to exclude participants with ocular pathology. This was followed by distance refraction using subjective technique to obtain the best correction. Subjective refraction technique, which relies on a participant's feedback, involves placing a series of trial lenses before the eye until a clear retinal image is perceived by the participant. ${ }^{20}$ Near vision was then assessed monocularly over distance refractive correction using a near Snellen chart, held at $40 \mathrm{~cm}$ from the participants' 
eyes. A near version of the tumbling ' $\mathrm{E}$ ' chart was used to assess the near visual acuity of illiterate participants. Any participant who needed an additional plus lens $\geq+1.00 \mathrm{D}$ to obtain a near visual acuity of N8 was considered presbyopic. The participant then responded to a pre-tested questionnaire which covered areas such as the near vision correction status, near visual needs and barriers to acquiring near vision correction.

\section{Statistical analysis}

Statistical analyses were carried out using Statistical Package for Social Sciences (IBM SPSS Statistics for windows, version 21, Armonk, NY, USA). Descriptive statistics including percentages, means and standard deviations were computed. Determinants of near vision correction were computed using Chi square statistical test and logistic regression analysis. Near vision spectacle coverage was computed by finding the proportion of the study participants who had near spectacle correction $(100 \times$ those with correction/ (those with correction + those without correction), while the "met near spectacle correction need" was computed as those with near spectacle correction in the presbyopic group. The "unmet need" was calculated as those without near vision correction or those with under corrected near correction. These definitions have been previously used in other population-based presbyopic studies. ${ }^{14,18}$

\section{Ethical consideration}

The study was conducted in accordance with the tenets of the Declaration of Helsinki. Ethical approval was obtained from the ethics review board of the Department of Optometry, University of Cape Coast (Reference number: FYP/15/0004). Participant's consent was sought before the study commenced. For those who could not read and write, the study aim and procedures were explained to them in local dialect (Fante). Participants without near vision spectacles were given spectacles after the examination procedures while participants who presented with other vision-related problems were referred to the nearest eye centre.

\section{Results}

Five hundred participants out of the 576 took part in the study giving a response rate of $87 \%$. Their mean age was $52.3 \pm 10.3$ years and $280(56 \%)$ were females while 220 $(44 \%)$ were males. The majority of participants $(76 \%)$ were educated having had at least a basic school certificate while $24 \%$ were uneducated. Details of participants' demographics are shown in table 1.

Table 1. Demographic characteristics of study participants

\begin{tabular}{llc} 
Variable & $\begin{array}{l}\text { Presbyopic } \\
\mathbf{n}(\%)\end{array}$ & $\begin{array}{l}\text { Non-presbyopic } \\
\text { n(\%) }\end{array}$ \\
\hline Age & $7(18)$ & $32(82)$ \\
$<40$ & $132(73)$ & $49(27)$ \\
$40-49$ & $136(84)$ & $26(16)$ \\
$50-59$ & $68(88)$ & $9(12)$ \\
$60-69$ & $33(80)$ & $8(20)$ \\
$\geq 70$ & $154(70)$ & $66(30)$ \\
Gender & $222(79)$ & $58(21)$ \\
Male & & \\
Female & $91(76)$ & $29(24)$ \\
Education & $177(73)$ & $64(27)$ \\
No formal education & $53(83)$ & $11(17)$ \\
Basic & $25(78)$ & $7(22)$ \\
Vocational & $30(70)$ & $13(30)$ \\
Secondary & & \\
Tertiary & $64(84)$ & $12(16)$ \\
Occupation & $132(72)$ & $52(28)$ \\
Unemployed & $180(75)$ & $60(25)$ \\
Unskilled & $\mathbf{3 7 6 ( 7 5 )}$ & $\mathbf{1 2 4}(\mathbf{2 5})$ \\
Skilled & & \\
Total & &
\end{tabular}

Of the 500 participants examined, 376 (75\%) were presbyopic by the study's definition. One hundred and twenty-five of the participants owned and presented with a near vision spectacle correction at the time of the study.
This represents a near vision spectacle coverage of 25 $\%(125 / 500 \times 100)$ and a $33 \%(125 / 376 \times 100)$ 'met need' among the presbyopic population. However, only $11 \%(56 / 500 \times 100)$ were comfortable with their current 
spectacles, with $14 \%(69 / 500 \times 100)$ reporting difficulty with near vision due to under correction when using their current prescription. The source and conditions of current spectacle for those who owned one are presented in table 2 . The unmet presbyopic need in the study population was $64 \%$ (those with under corrected near correction (69) + those with uncorrected presbyopia $(251))=100 \times$ $(69+251) / 500)$.

Table 2. Source and state of spectacle for participants with "met need"

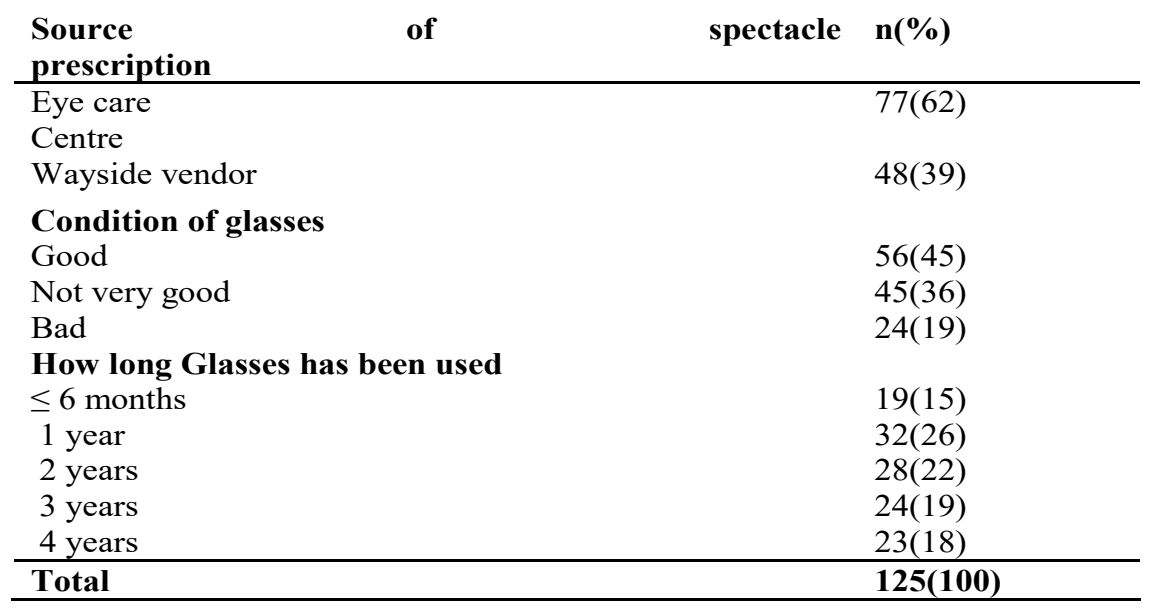

The mean near addition lens (near ADD) required was 1.50D \pm 1 . 00D. Univariate analysis of "met need" and socio demographic factors revealed that "met need" was associated with age and educational level (Table 3).

Table 3. Results of Univariate analysis of socio-demographic variables on 'met near vision spectacles need'.

\begin{tabular}{lll}
\hline Demographics & $\mathbf{X}^{\mathbf{2}}$ & $\boldsymbol{p}$-value \\
\hline Gender & 0.72 & 0.397 \\
Age & 17.00 & 0.002 \\
Educational level & 30.71 & 0.000 \\
Occupation & 2.72 & 0.606 \\
\hline
\end{tabular}

Further analysis using logistic regression revealed statistically significant relationships between met presbyopic need and age (statistical significance was observed in those in the $5^{\text {th }}$ and $6^{\text {th }}$ decades), and educational level (Table 4). 
Table 4. Results of logistic regression analysis of socio-demographic variables on

'met near vision spectacles need'

\begin{tabular}{|c|c|c|c|c|c|}
\hline Variable & $\begin{array}{l}\text { No. } \\
\text { examin } \\
\text { ed } \\
\text { n(\%) } \\
\end{array}$ & $\begin{array}{l}\text { No. of } \\
\text { 'met } \\
\text { need' } \\
\text { n(\%) }\end{array}$ & $\begin{array}{l}\text { Adjusted } \\
\text { OR }(95 \% \text { CI })\end{array}$ & & $\begin{array}{l}p \text { - } \\
\text { value }\end{array}$ \\
\hline \multicolumn{6}{|l|}{ Gender } \\
\hline Male & $\begin{array}{l}220(44 . \\
0)\end{array}$ & $53(42.0)$ & Reference & & - \\
\hline Female & $\begin{array}{l}280(56 . \\
0)\end{array}$ & $73(58.0)$ & $1.03(0.64,1.65)$ & & 0.90 \\
\hline \multicolumn{6}{|l|}{ Occupation } \\
\hline Unemployed & $76(15.2)$ & $23(18.3)$ & Reference & & - \\
\hline Skilled & $\begin{array}{l}184(36 . \\
8)\end{array}$ & $41(32.5)$ & $0.52(0.25,1.28)$ & & 0.17 \\
\hline Unskilled & $\begin{array}{l}240(48 . \\
0)\end{array}$ & $62(49.2)$ & $\begin{array}{l}0.66 \\
1.60)\end{array}$ & $(0.34$ & 0.44 \\
\hline \multicolumn{6}{|l|}{ Age } \\
\hline$<40$ & $39(8)$ & $0(0.0)$ & & & - \\
\hline$\dagger^{\dagger} 0-49$ & $181(36)$ & $32(25.4)$ & Reference & & - \\
\hline $50-59$ & $32)^{162(}$ & $59(46.8)$ & $2.70(1.55,4.68)$ & & 0.00 \\
\hline $60-69$ & $15)^{77(}$ & $27(21.4)$ & $2.36(1.18,4.72)$ & & 0.02 \\
\hline$\geq 70$ & $41(8)$ & $6.3)^{8(}$ & $2.01(0.66,6.09)$ & & 0.22 \\
\hline \multicolumn{6}{|l|}{ Education } \\
\hline No formal education & $\begin{array}{l}120(24 . \\
0)\end{array}$ & $11(8.7)$ & Reference & & - \\
\hline Basic & $\begin{array}{l}241(48 . \\
2)\end{array}$ & $65(51.6)$ & $6.58(3.04,14.24)$ & & $\begin{array}{l}\mathrm{p}<0.00 \\
1\end{array}$ \\
\hline Vocational & .4) $32(6$ & $24(19.0)$ & $10.41(4.12,26.31)$ & & $\begin{array}{l}\mathrm{p}<0.0 \\
01\end{array}$ \\
\hline Secondary & $64(12.8)$ & $10(7.9)$ & $8.05(2.67,24.22)$ & & $\begin{array}{l}\mathrm{p}<0.00 \\
1\end{array}$ \\
\hline Tertiary & $43(8.6)$ & $16(12.8)$ & $14.62(5.03,42.44)$ & & $\begin{array}{l}\mathrm{p}<0.00 \\
1\end{array}$ \\
\hline
\end{tabular}

Results of barriers to obtaining near vision spectacle in those with 'unmet need' included: lack of felt need for near vision correction $64(26 \%)$, unaware of available intervention/correction $55(22 \% \%)$, financial constraint 53 $(21 \%)$, lack of access to eye care facilities 32 (13\%), other barriers such as concerns about perception of spectacle wear $29(12 \%)$, and more than one barrier $12(5 \%)$. Many participants $188(50 \%)$ were willing to obtain a pair of near vision spectacles if the cost was between 5-30 Ghana Cedis (GHS) (approximately 2-8 US \$), while 154 (41 $\%$ ) were willing to pay if the cost of was GHS 5 (2 US \$) only. Thirty-four $(9 \%)$ were willing to pay as much GHS 30 (8 US \$) or more for near vision spectacle. Two hundred and thirty-nine $(63.8 \%)$ of the participants wanted the National Health Insurance Scheme to cover the cost of near vision spectacles, $18(5 \%)$ did not support the idea and 119 (32\%) were indifferent.

\section{Discussion}

Our study sought to profile near vision spectacle coverage and barriers to near vision spectacle coverage in the
Cape Coast Metropolis of Ghana. This is usually the first step towards planning near vision correction (presbyopic) services in the community. ${ }^{21}$ The response rate for our study was high, which is comparable to other related presbyopia studies. ${ }^{7,14,18}$ This high response rate could be partly explained by a desire on the part of participants to be provided with corrections for their near vision problems. Also, the enumeration and recruitment strategies could have had an impact on the high turnout. The mean age of study participants compares to a similar study in Nigeria, ${ }^{14}$ and could be the reason for a low near ADD observed in the study participants given that younger presbyopes normally require lower ADD. Majority of participants in our study were literate and people with high literacy have been reported to engage in near visually demanding tasks such as reading. ${ }^{14}$ Consequently, absence of near correction in such persons could affect their quality of life and well-being.

The spectacle coverage rate observed in our study was lower compared to a recent study in Nigeria. ${ }^{22}$ While their study participants were staff of a health facility who were 
more likely to be educated and own spectacles for near tasks such as reading, our study participants were adults in the community with different educational and occupational backgrounds. The low spectacle coverage in this area suggests that it is a high priority area for targeted intervention using WHO recommendation. ${ }^{23}$ Public health strategies to increase presbyopic correction coverage could be undertaken by optometrists and other eye care professionals in a region which has a reported low refractive services. ${ }^{24}$ Results of met presbyopic need in our study are similar to those of Timor- Leste study ${ }^{18}$ in terms of the proportion of the study population with "met need" and factors which are associated with met need. Age and educational level were associated with met presbyopic need. With increasing age, the progressive loss of ability to accommodate will increase the severity of presbyopia which could be a compelling reason to seek correction. This may help explain why adults in their fifth and sixth decades in particular, were likely to have their near vision correction need met. The use of near vision correction for work-related activities maybe pronounced in this age group and could explain this finding even though no statistically significant association between "met need" and occupation was observed. Similarly, literate adults would be more willing to get near corrections as reading and execution of other near vision related tasks become difficult. While some previous studies have found gender as a determinant of met presbyopic needs, ${ }^{18,25,26}$ our study did not find that. This could be due to our study location being predominantly urban, compared to the other studies which were conducted in rural settlements, where cultural factors such as unequal access to eye care by males and females, markedly influence the gender difference in met presbyopic need. ${ }^{26}$ The majority of those who had a near vision spectacle correction had obtained them from an eye care centre. This is a positive finding as they may have been seen by a qualified eye care professional, and may have had a comprehensive eye examination, compared to those who may have obtained their correction from a wayside vendor for example.

Barriers to obtaining near correction were mainly due to lack of felt need, financial constraint and lack of awareness of available intervention. These findings are consistent with those of previous studies conducted in developing countries. ${ }^{14,18}$ The benefits of having near vision correction for economic, educational, and recreational activities are enormous. Consequently, increased public health ed-

African Health Sciences Vol 17 Issue 2, June, 2017 ucation in the communities could help increase interest in near vision correction, and raise awareness about available interventions. Provision of affordable spectacles in both routine clinical eye care, and during community outreach programmes could help to overcome the cost barrier. This is important as the study found that many participants were willing to acquire a pair of near correction if the cost was US $\$ 2$ or less, which is far below a previously reported cost of $\$ 5.8$ Also, inclusion of near vision spectacles to the list of prosthesis covered by the national health insurance scheme, which is the main method of health financing in Ghana, could help to improve near vision spectacle coverage.

\section{Conclusion}

In summary, our study found a low near vision spectacle coverage for a study population with a high prevalence of presbyopia. This and several barriers to obtaining a near vision correction reported in this study warrant mitigation through public awareness and health promotion messages. Education on the benefits of near vision correction, and provision of affordable spectacle services (including national health insurance financing of near vision spectacles) should be developed to address this challenge.

\section{Acknowledgement}

The authors extend their gratitude to the study participants and assembly men in all the clusters for their participation.

\section{Conflict of interest:}

The authors have no conflict of interest to declare.

\section{References:}

1. Hickenbotham A, Roorda A, Steinmaus C, et al. Meta-Analysis of Sex Differences in Presbyopia. Invest Ophthalmol Vis Sci 2012; 53: 3215-3220.

2. Kumah DB, Lartey SY and Amoah-Duah K. Presbyopia among public senior high school teachers in the Kumasi metropolis. Ghana Med J 2011; 45: 27-30.

3. Charman WN. The eye in focus: accommodation and presbyopia. Clin Exp Optom 2008; 91: 207-225.

4. Frick KD, Joy SM, Wilson DA, et al. The Global Burden of Potential Productivity Loss from Uncorrected Presbyopia. Ophthalmology 2015; 122: 1706-1710.

5. Holden BA, Fricke TR, Ho SM, et al. Global Vision Impairment Due to Uncorrected Presbyopia. Arch Ophthalmol 2008; 126: 1731-1739. 
6. Patel I and West SK. Presbyopia: prevalence, impact, and interventions. Comm Eye Health 2007; 20: 40-1.

7. Nirmalan PK, Krishnaiah S, Shamanna BR, et al. A population-based assessment of presbyopia in the state of Andhra Pradesh, South India: The Andhra Pradesh Eye Disease Study. Invest Ophthalmol Vis Sci 2006; 47: 2324-2328.

8. Ntodie M. Situational analysis of refractive error and low vision services in the northern and central regions of Ghana. MSc Dissertation Sept 2013: 27.

9. Ocansey S, Kumi-Kyereme A, Awusabo-Asare K, et al. Utilization of Eye Care Services among Ghanaian Elderly Population: Evidence from a Peri-Urban Community. Ophthalmol Research 2013; 1: 89-101.

10. Ghana Statistical Services. 2010 Population and housing census, national analytical report.

11. Orr P, Barron Y, Schein OD, et al. Eye care utilization by older Americans - The SEE project. Ophthalmology 1999; 106: 904-909.

12. Holden BA, Tahhan N, Jong M, et al. Towards better estimates of uncorrected presbyopia. Bull World Health Organ 2015; 93: 667-667.

13. Marmamula S, Khanna RC, Narsaiah S, et al. Prevalence of spectacles use in Andhra Pradesh, India: Rapid Assessment of Visual Impairment project. Clin Exp Ophthalmol 2014; 42: 227-234.

14. Umar MM, Muhammad N and Alhassan MB. Prevalence of presbyopia and spectacle correction coverage in a rural population of North West Nigeria. Clin Ophthalmol 2015; 9: 1195-201.

15. Naidoo KS, Jaggernath J, Martin C, et al. Prevalence of Presbyopia and Spectacle Coverage in an African Population in Durban, South Africa. Optom Vis Sci 2013; 90: 1424-1429.

16. Ghana Statistical Services. 2010 Population and housing census: summary report of final results.
17. Cape Coast Metropolitan Assembly. Annual composite progress report (2013), 2013.

18. Ramke J, du Toit R, Palagyi A, et al. Correction of refractive error and presbyopia in Timor-Leste. $\mathrm{Br} J \mathrm{Oph}$ thalmol 2007; 91: 860-866.

19. Burke AG, Patel I, Munoz B, et al. Population-based study of presbyopia in rural Tanzania. Ophthalmology 2006; 113: 723-727.

20. Woodman-Pieterse EC, De Souza NJ and Vincent SJ. The influence of a novel simulated learning environment upon student clinical subjective refraction performance: A pilot study. Clin Exp Optom 2016; 99: 342-9.

21. Sherwin JC, Keeffe JE, Kuper H, et al. Functional presbyopia in a rural Kenyan population: the unmet presbyopic need. Clin Exp Ophthalmol 2008; 36: 245-251.

22. Balarabe AH, Adamu S and Musa R. Presbyopia among health workers in a tertiary hospital in north western Nigeria. Sub-Saharan Afr J Med 2015: 10-3.

23. WHO. Elimination of avoidable visual disability due to refractive errors: report of an informal planning meeting. Report no. WHO/PBL/00.79.

24. Ntodie M, Danquah L, Kandel H, Abokyi S. Toward eliminating blindness due to uncorrected refractive errors: assessment of refractive services in the northern and central regions of Ghana. Clin Exp Optom 2014; 97: 511-515.

25. Laviers HR, Omar F, Jecha H, et al. Presbyopic Spectacle Coverage, Willingness to Pay for Near Correction, and the Impact of Correcting Uncorrected Presbyopia in Adults in Zanzibar, East Africa. Invest Opbthalmol Vis Sci 2010; 51: 1234-1241.

26. Muhammad RC and Jamda MA. Presbyopic correction coverage and barriers to the use of near vision spectacles in rural Abuja, Nigeria. Sub-Sabaran Afr J Med 2016; 3: $20-24$. 